\title{
METODOLOGIAS ATIVAS: FERRAMENTA DA EDUCAÇÃO INCLUSIVA
}

\author{
1, ${ }^{*}$ Jairo José de Souza and ${ }^{2}$ Eduardo Cardoso de Moraes \\ ${ }^{1}$ Professor da Universidade Aberta do Brasil-UAB. \\ ${ }^{2}$ Professor do Instituto Federal de Alagoas-IFAL
}

\section{ARTICLE INFO}

\section{Article History:}

Received $17^{\text {th }}$ March, 2021

Received in revised form

$26^{\text {th }}$ April, 2021

Accepted $11^{\text {th }}$ May, 2021

Published online $26^{\text {th }}$ June, 2021

\section{Key Words:}

Aluno com Necessidades Educacionais específicas; Educação Inclusiva; Metodologias Ativas; Prática Docente.

\section{*Corresponding author:}

Jairo José de Souza

\begin{abstract}
$\mathrm{O}$ artigo aborda sobre as metodologias ativas, suas diversas definições, e como contribuem para o processo escolar que envolve prática de ensino, aluno e professor. Assim, cabe refletir sobre as metodologias ativas e as alternativas que o seu uso proporciona no ambiente escolar, levando em conta os vários modelos de ensino, o processo de adquirir o conhecimento, os métodos que serão utilizados para esse fim, e analisando ainda a contribuição dessas variáveis no tocante à inclusão escolar do aluno com necessidades educacionais específicas e ao papel do professor nesse contexto. Para tanto, realizou-se um levantamento bibliográfico a partir de teorias voltadas para o processo de ensino/aprendizagem pautadas em autores como Freire (1999), Zabala (1998), Piaget (1994), Dewey (1979), M. Silva (2005), Moreira (2006), dentre outros. Salientamos que este estudo também procura refletir sobre o sentido que a educação inclusiva ganha na prática dos professores em sala de aula.
\end{abstract}

Copyright (C) 2021, Jairo José de Souza and Eduardo Cardoso de Moraes. This is an open access article distributed under the Creative Commons Attribution License, which permits unrestricted use, distribution, and reproduction in any medium, provided the original work is properly cited.

Citation: Jairo José de Souza and Eduardo Cardoso de Moraes. "Metodologias ativas: ferramenta da educação inclusiva”, International Journal of Development Research, 11, (06), 47962-47965.

\section{INTRODUCTION}

Considera-se que um dos principais desafios e objetivos de um professor é que seja competente e humano na arte do ensino, consoante Zabala (1998). Esses atributos são oriundos tanto do conhecimento quanto da experiência, vivenciados numa prática escolar onde se procura ter o controle das variáveis que interferem no desempenho profissional. Para tanto, conhecer essas variáveis permitem ao professor planejar o desenvolvimento do processo ensino/aprendizagem, operacionalizar a sistemática planejada e avaliar o resultado alcançado. Portanto, para um efetivo modelo de ensino, o planejamento, a aplicação e a avaliação são indispensáveis. $\mathrm{O}$ ato de analisar a prática educativa do ensinar envolve as diversas opções que o professor dispõe para utilizar na sua sala de aula. Embora recorra-se bastante à unidade básica do livro adotado e à atividade ou tarefa que decorre a seguir, diversificado é o rol de possibilidades: exposição, debate, leitura, pesquisa bibliográfica, observação, exercícios, estudo etc. Torna-se assim fundamental escolher as sequências didáticas, que são "conjunto de atividades ordenadas, estruturadas e articuladas para a realização de certos objetivos educacionais, que têm um princípio e um fim conhecidos tanto pelos professores como pelos alunos" (ZABALA, 1998, p.18). Significa observar a análise da prática educativa por meio de atividades relacionadas ao processo de ensino/aprendizagem, incluindo também o que se espera do professor e dos alunos; o papel da organização da aula para uma educação inclusiva; a forma como são organizados os conteúdos; a existência, as características, o uso dos materiais curriculares e outros recursos didáticos; o sentido que tem o papel da avaliação. Desse modo, cabe refletir sobre as metodologias ativas e as alternativas que o uso delas proporciona no ambiente escolar. Os vários modelos de ensino, o processo de adquirir o conhecimento e os métodos que serão utilizados para esse fim, sem nos esquecermos da análise da contribuição deles no tocante à inclusão escolar do aluno com necessidades educacionais específicas e do papel do professor nesse contexto. As metodologias ativas têm como um dos seus percussores o professor inglês Reginald Williams Revans (1907-2003). Segundo ele, as metodologias ativas vão além de escutar, de ler, escrever ou discutir. Não é uma única ferramenta ou técnica. Vai além, pois requer "um ambiente propício, diversas formas de comunicações e diversas estratégias de ensino/ aprendizagem" (A PEDRA, 2017). Além do mais, embora "Vygotsky, Freire, Rogers, Dewey não citem explicitamente as metodologias ativas, todos eles defendiam que os princípios que as regem são importantes para o processo de ensino/aprendizagem" (ANDRAGOGIA BRASIL, 2018).

Referencial Teórico: Quando se tem por referência metodologias ativas, alguns ainda pensam em fórmulas rebuscadas e práticas complexas. Quando o professor profere sua tradicional aula 
expositiva, com avaliações e trabalhos respectivos, isso também pode ser considerado uma metodologia ativa. A questão não está então no instrumental didático que o professor utiliza, e sim no envolvimento do aluno em relação ao que está sendo proposto pelo professor. As metodologias ativas, independente da prática escolar, estão relacionadas à formação de sujeitos autônomos e críticos, que se percebem reflexivos e, consequentemente, capazes de alterar o próprio processo formativo, consoante Freire (2006). As metodologias ativas são alternativas aos feudos pedagógicos estabelecidos nas instituições educacionais, ao estabelecerem um contraponto ao predomínio de determinadas sistemáticas convencionais de ensino, ainda centradas no processo, e não no aluno. De acordo com Macedo et al. (2018), as metodologias ativas assentam-se na concepção de educação crítico-reflexiva com base em estímulo no processo de ensino-aprendizagem, resultando em envolvimento por parte do educando na busca pelo conhecimento. Assim, a prática de ensino já não gera passividade, com o aluno já não sendo aprendiz, e sim protagonista. O professor, por sua vez, deixa a postura bancária, assumindo o papel de orientador. Já para Mitre et al. (2008), as metodologias ativas se valem da problematização como estratégia de ensino/aprendizagem, com o intuito de ir em busca do aluno e motivá-lo. Logo, diante do problema, ele se detém, examina, reflete, relaciona a sua história e passa a ressignificar suas descobertas. Ao problematizar o aluno é levado ao contato com as informações e à produção do conhecimento, principalmente com a finalidade de solucionar os impasses e promover o seu próprio desenvolvimento. O construtivismo também reforça a importância das metodologias ativas no processo educacional. A criança em formação contínua, refletindo constantemente a si mesma e aos seus atos, precisa que o professor utilize essas ferramentas educacionais para auxiliá-la nesse processo de adaptação ao meio social e concomitantemente de transformação desse próprio meio, tornando-a capaz de ser protagonista no viver escolar e na vida. Segundo Piaget (1993), quando o professor antecipa a descoberta que a criança poderia no devido tempo ela mesma desvendar, está extraindo do processo escolar toda a motivação que deve necessariamente permear o ensino. O professor deve ser o facilitador, à medida que traz o aluno para o mundo da inovação, tornando-o assim sujeito das suas próprias descobertas.

Ferramenta da Educação Inclusiva: As metodologias ativas visam desenvolver formas de aprendizagem. O professor nesse processo utiliza-se da mediação buscando favorecer a autonomia do aluno, despertar a sua curiosidade, estimular o aluno a refletir sobre as suas decisões individuais e coletivas, que são influenciadas pelas próprias experiências vivenciadas pelo aluno na sua prática social, conforme Borges e Alencar (2014). Dessa forma é necessário utilizar os mais diversos tipos de modelos, métodos, técnicas, explorando situações concretas, dinâmicas, filmes, vídeos; as intervenções interdisciplinares; recursos audiovisuais, filmagens, gravações e fotografias; as falas dos alunos, fazendo um registro da participação deles quando da realização de aula expositiva ou de cunho mais tradicional. As metodologias ativas não se resumem a uma técnica, a um método. O professor media o processo de interação para que ocorra a aprendizagem, não importando se a prática de ensino requer uma diversidade de recursos maior ou não.

Quanto ao processo de adquirir conhecimento nesse contexto, analisemos o que disse Dewey (1979, p. 165):

Analisando o papel da reflexão na experiência, observa-se que o pensamento, ou reflexão, é o discernimento da relação entre o que tentamos fazer e o que acontece como consequência. Se não tivermos abertura intelectual, não é possível uma experiência significativa, e, sendo assim, percebemos dois diferentes tipos de experiência conforme à proporção que damos à reflexão, denominadas pelos psicólogos de experiência e erro.

Portanto, a reflexão tem papel importantíssimo na experiência do aluno e do professor. Ela é a porta para a abertura intelectual, sendo significativa para as diferentes práticas na aquisição de saberes e conhecimento. Pontua Wall et al. (2008) que o processo de ensino ocorre quando o educando é o protagonista, tem autonomia sobre seu processo de aprendizagem, e os educadores desempenham o papel de facilitadores. Para Gomes et al. (2018), por sua vez, as metodologias ativas têm como objetivo colocar as dificuldades e as necessidades dos educandos no centro do processo de aprendizagem, enquanto os professores deixam de ter o papel de meros transmissores de conhecimentos, passando a ser aquele que estimula o desenvolvimento de capacidades dos discentes. O que fica claro na visão desses e de outros autores anteriormente mencionados é que as metodologias ativas constituem uma ferramenta da educação inclusiva, especialmente quando coloca o aluno na condição de sujeito histórico e reflexivo.

Aluno com Necessidades Educacionais Específicas: Para incluir o aluno com necessidades educacionais específicas, devido às particularidades que abrangem o respectivo processo de ensino/aprendizagem, é necessário refletir sobre a metodologia estabelecida por Zabala (1998), definindo o conteúdo baseado na sequência de atividades e formatando um planejamento operacional. É necessário também incentivar relações interativas, envolvendo um aluno com o outro independente das especificidades de cada um; estabelecer a organização social da aula, visto estar lidando com sujeitos históricos; promover a utilização dos espaços e do tempo, transformando a sala de aula num local de dinâmica própria; definir uma maneira de organizar os conteúdos, a fim de que a transparência seja a base do relacionamento entre todos; encontrar o sentido e o papel da avaliação, tornando um instrumento de constante reflexão para o grupo. Dentre as contribuições das metodologias ativas, podemos citar um projeto desenvolvido na Universidade Federal do ABC (2011-2013), em que se partiu da experiência intitulada habitus professoral. Trata-se do "caminho teórico-metodológico da construção de um recurso explicativo dos comportamentos de professores, sobretudo, do re-endereçamento do objeto de estudo do ato de ensinar na sala de aula" (M. SILVA, 2005). É uma arquitetura que "encontra nas ideias de Bourdieu e de Thompson a representação da experiência, da prática docente" (M. SILVA, 2005). Ou seja, encontrar o melhor equilíbrio entre teoria e prática do professor, levando-se em consideração as características específicas da natureza de cada um desses saberes, que trazem implicações aos modos por meio dos quais esses saberes são apreendidos.

As sequências didáticas contribuem também para o processo de formação inicial, que "possibilita aos seus participantes antecipar uma série de desafios aos quais eles seriam expostos apenas na fase de iniciação" (VINTURI et al., 2014). Com isso, o professor é realmente inserido na contextualização do ambiente escolar, possibilitando a vivência entre a teoria e a experiência, que é de primordial importância para a prática docente. As metodologias ativas possibilitam ao aluno a construção do conhecimento crítico. Moreira (2006) afirma que a aprendizagem crítica é aquela constituída da interação do conhecimento a adquirir e do conhecimento prévio. Daí que o cerne da metodologia ativa é a capacidade do aluno previamente construir um conhecimento que venha a contribuir com o que está sendo discutido em sala de aula. Sem essa conscientização do aluno, uma metodologia ativa dificilmente alcança seus objetivos, embora seja preciso reconhecer que o professor ainda é o principal responsável para que isso não venha a acontecer.

Ele é aquele que vai motivar, aquele que vai facilitar. No âmbito da inclusão escolar do aluno com necessidades educacionais específicas, as metodologias ativas são capazes de auxiliar nesse processo à medida em que esses alunos requerem um processo de acompanhamento individual que exige do professor e demais educadores envolvidos uma ressignificação das práticas correntes. A questão sujeito e mundo, discorrida por Freire (1999), reflete que as metodologias ativas são ferramentas que favorecem mudanças individuais e, consequentemente, sociais. Logo, a inclusão do aluno com necessidades educacionais específicas é favorecida pela inserção das metodologias ativas na prática docente. Diante das mais variadas perspectivas que as metodologias ativas trazem à inclusão do aluno com necessidades educacionais específicas, podemos destacar a autonomia, que deve ser possibilitada a todos. "No processo de 
aprendizagem só aprende verdadeiramente aquele que se apropria do aprendido, transformando-o em apreendido, com o que pode, por isto mesmo, reinventá-lo; aquele que é capaz de aplicar o aprendido apreendido a situações existenciais concretas" (FREIRE, 1983, p. 27). Ante o exposto, refletimos a autonomia do aluno no sentido de apropriação do saber com o objetivo de transformação social. Ainda é pertinente ao aluno com necessidades educacionais específicas, dentro do viés construtivista, a sua própria reflexão. A base assentada para que isso ocorra encontra-se no diálogo, na metodologia científica e na aprendizagem significativa.

Consoante Macedo et al. (2018), ao acordar para o mundo da reflexão, o aluno é acionado para interagir e o conhecimento acaba sendo impregnado nele. As metodologias ativas também propiciam a participação efetiva do aluno no processo de construção do conhecimento, visto que ainda é uma realidade o modelo de ensino baseado no professor como protagonista no âmbito escolar, embora na educação inclusiva o aluno com necessidades educacionais específicas seja acompanhado também por outros educadores. $\mathrm{O}$ momento educacional atual, em função das mudanças que ocorrem na própria sociedade, está exigindo cada vez mais um cenário democrático dentro da sala de aula, onde o professor não deve e não pode mais ser o destaque em meio ao processo de ensino/aprendizagem. Conforme pontua Pedrosa et al. (2011), no processo de ensino/aprendizagem há promoção de troca de conhecimento, de vivências e sentimentos entre aluno-professor, daí a importância de se encadear nessa ação uma busca pela igualdade, de modo que a construção educacional, e consequentemente social, seja fruto de diferentes sujeitos históricos.

\section{CONSIDERAÇÕES FINAIS}

Este artigo assentou-se em diversos estudos sobre metodologias ativas e como os mais diversos autores as abordam. As metodologias ativas não estão relacionadas às fórmulas e técnicas, sejam elas simples ou complexas, pois quando o professor se utiliza da aula tradicional também pode fazer uso dessa ferramenta, uma vez que o que importa não é o instrumental didático, mas sim o envolvimento do aluno em relação ao que está sendo proposto pelo professor, e o papel do professor como facilitador do processo de ensino/aprendizagem. No que diz respeito à inclusão escolar do aluno com necessidades educacionais específicas, as metodologias ativas mostram-se como ferramenta capaz de contribuir nesse processo inclusivo, à medida que esse discente requer um acompanhamento pessoal mais detalhado, consoante Zabala (1998).

O que exige do professor e demais educadores envolvidos no ambiente escolar uma ressignificação das práticas correntes, tornando-se todos participantes das mudanças individuais e sociais que a educação inclusiva possibilita. A inclusão do aluno com necessidades educacionais específicas passa pela reflexão em relação a essas especificidades na prática docente. As metodologias ativas abrem espaço ao aluno para construção de um conhecimento crítico, dando-lhe a possibilidade de formatar e de explorar previamente conhecimentos que venham a contribuir com o que está sendo discutido em sala de aula. Portanto, é nesse contexto de reflexão sobre a importância da participação do aluno que as metodologias ativas também favorecem à prática do professor no papel de facilitador. Conforme destacam Fujita et al. (2016), um dos pilares fundamentais das metodologias ativas está assentado na autonomia, colocando o aluno no centro do processo, tornando-o protagonista na elaboração do seu próprio aprendizado.

Assim, entendemos ser essencial um olhar particular à inclusão do aluno com necessidades específicas e às metodologias ativas como instrumento de suporte para a educação inclusiva, superando um clico ultrapassado de ensino/aprendizagem gerador de exclusão e, consequentemente, da não transformação social. $\mathrm{O}$ total de pessoas com deficiência representa $24 \%$ da população brasileira (IBGE EDUCA, 2010). Praticamente 1/4 dela. Uma representatividade altamente significativa. Por outro lado, esse mesmo grupo representa apenas $0,9 \%$ no universo das carteiras assinadas (DIEESE, 2017). Fazendo uma análise entre esses números expressivamente dicotômicos, chegamos à conclusão de que esse histórico paradoxo necessariamente passa pelo viés da não inclusão no ambiente escolar da pessoa com deficiência e, consequentemente, da não permanência do aluno com necessidades educacionais específicas. Julgamos ser oportuno trazer essa discussão para a pauta. O que está em jogo é uma parcela representativa da população brasileira. Iremos continuar vivendo do sacrifício desse ou daquele professor mais preocupado com as diretrizes da educação inclusiva? Quando institucionalmente não se está preparado para receber o aluno com necessidades educacionais específicas, os potencialmente excluídos permanecem sem esperança. Todo trabalho acadêmico que faça pensar a esse respeito tem uma importância social. Só avançaremos efetivamente em termos de educação inclusiva se formos capazes de compreender que ninguém, ninguém mesmo, pode ficar para trás.

\section{REFERÊNCIAS}

Andragogia Brasil. 2018. Metodologias Ativas: conceito e aplicação. In: Andragogia Brasil. Recuperado de https://andragogiabrasil. com.br/metodologias-ativas/.

Borges, T.\& Alencar, G.2014. Metodologias ativas na promoção da formação crítica do estudante: o uso das metodologias ativas como recurso didático na formação crítica do estudante do ensino superior. Cairu em Revista. Jul/Ago Ano 03, n 04, p. 119-143. Recuperado de https://ufsj.edu.br/portal2-repositorio/ File/ napecco/Metodologias/Metodologias\%20Ativas\%20na\%20Promo cao\%20da\%20Formacao.pdf.

Dewey, J.1959. Democracia e educação: introdução à filosofia da educação. 3a. ed. São Paulo: Nacional.

Dieese. 2017. Movimentação no mercado de trabalho: rotatividade, intermediação e proteção ao emprego/. Departamento Intersindical de Estatística e Estudos Socioeconômicos - São Paulo, SP: DIEESE, 2017. Recuperado de https://www.dieese. org.br/livro/2017/rotatividade.pdf.

Freire, P. 1983. Extensão ou Comunicação? 8. ed. Rio de Janeiro: Paz e Terra.

Freire, P. 1999. Pedagogia da autonomia: saberes necessários à prática educativa. 13. ed. São Paulo: Paz e Terra.

Freire, P.2006. Pedagogia da esperança: um reencontro com a pedagogia do oprimido. São Paulo: Paz e Terra.

Fujita, JALM.et al.2016. Uso da metodologia da problematização como Arco de Maguerez no ensino sobre brinquedo terapêutico. Revista Portuguesa de Educação, v. 29, n. 1.

Gomes, R.et al. 2018. Avaliação de percepções sobre gestão da clínica em cursos orientados por competência. Ciência \& Saúde Coletiva, v. 23, 17-28.

Ibge educa. Conheça o Brasil-População. Pessoas com deficiência. Recuperado de https://educa.ibge.gov.br/jovens/conheca-obrasil/populacao/20551-pessoas-com-deficiencia.html.

Macedo, KDS. et al.2018. Metodologias ativas de aprendizagem: caminhos possíveis para inovação no ensino em saúde. Escola Anna Nery 22(3). Recuperado de https://www.scielo.br/ pdf/ean/v22n3/pt_1414-8145-ean-22-03-e20170435.pdf.

Mitre, SM. et al. 2008.Metodologias ativas de ensino-aprendizagem na formação profissional em saúde: debates atuais. Ciência e Saúde Coletiva, Rio de Janeiro, v. 13

Moreira, MA. 2006. A teoria da aprendizagem significativa e sua implementação em sala de aula. Brasília: Editora da UnB.

Pedrosa, IL. et al. 2011. Uso de metodologias ativas na formação técnica do agente comunitário de saúde. Trab. educ. saúde (Online), vol.9, no.2, p.319-332. ISSN 1981-7746.

Piaget, J. 1993. A representação do espaço na criança. Porto Alegre: Artes Médicas.

Silva, M. 2005. O habitus professoral: o objeto dos estudos sobre o ato de ensinar na sala de aula. Revista Brasileira de Educação, 29, 152-163.

Unicamp. 2017. Aprendizagem ativa é mais antiga do que você imagina. In: A Pedra.Recuperado de https://www.blogs. unicamp.br/apedra/2017/10/12/aprendizagem-ativa-e-maisantiga-do-que-voce-imagina/. 
Vinturi, EF.et al.2014. Sequências didáticas para a promoção da alfabetização científica: relato de experiência com alunos do Ensino Médio. Revista Experiências em Ensino de Ciências [online], v. 9, n. 3, pp. 11-25. Recuperado de http://if.ufmt.br/eenci/artigos/Artigo_ID251/v9_n3_a2014.pdf.
Wall, ML. et al. 2008. The experienceofundergoing a TeachingInternshipapplyingactivemethodologies. Acta Paulista de Enfermagem, v. 21, n. 3, p. 515-519.

Zabala, A. 1998. A prática educativa: Como Ensinar. Porto Alegre: Artmed, 1998. 